\title{
Multilevel data analysis: What? Why? How?
}

\author{
Jeevanantham Rajeswaran, $\mathrm{PhD},{ }^{\mathrm{a}}$ and Eugene $\mathrm{H}$. Blackstone, $\mathrm{MD}^{\mathrm{a}} \mathrm{b}$
}

\footnotetext{
From the ${ }^{\mathrm{a}}$ Department of Quantitative Health Sciences, Research Institute, and ${ }^{\mathrm{b}}$ Department of Thoracic and Cardiovascular Surgery, Heart and Vascular Institute, Cleveland Clinic, Cleveland, Ohio.

Disclosures: Authors have nothing to disclose with regard to commercial support.

Received for publication June 8, 2017; accepted for publication June 12, 2017; available ahead of print July 12, 2017.

Address for reprints: Jeevanantham Rajeswaran, PhD, Department of Quantitative Health Sciences, Cleveland Clinic, 9500 Euclid Ave/Desk JJN3, Cleveland, OH 44195 (E-mail: rajeswj@ccf.org).

J Thorac Cardiovasc Surg 2018;155:210-1

$0022-5223 / \$ 36.00$

Copyright $\Subset 2017$ by The American Association for Thoracic Surgery

http://dx.doi.org/10.1016/j.jtcvs.2017.06.027
}

Parolari and colleagues ${ }^{1}$ report a prospective study of variables associated with arterial and venous coronary artery bypass graft occlusion by computed tomographic angiography 15 to 21 months after surgery, with a focus on D-dimer elaboration after surgery. They imaged 503 grafts in 179 patients. To the average reader, data analysis should be simple: count the occluded grafts, divide by 503 to obtain the proportion occluded (perhaps expressed as a percentage), then use logistic regression analysis to identify risk factors for occlusion. Instead, the reader is met with unfamiliar terms such as "mixed model" logistic regression. What is going on?

On closer reflection, the reader comes to realize that each patient had, on average, 3 grafts. All 3 were exposed to the same D-dimer levels and other individual patient variables. This means that grafts in a given patient are not completely independent of each other. How do we sort this out? This is a challenge we face daily as reviewers for this Journal, and something with which the authors had to contend.

For this commentary, we will call such data "multilevel data" — graft-level and patient-level—that requires an analysis that accounts for its multilevel structure.

\section{WHAT?}

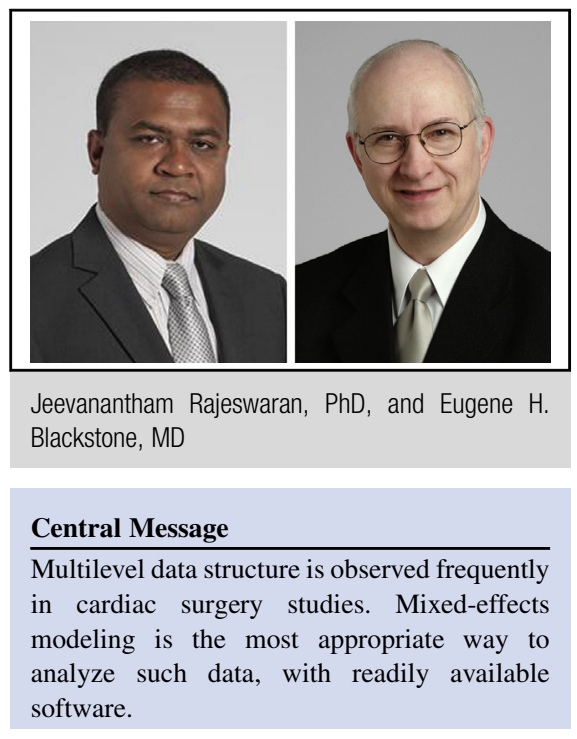

See Article page 200

In many clinical studies, data are naturally multilevel ("nested"). The data of Parolari and colleagues ${ }^{1}$ have a 2-level structure. Consider a more complex study of patient-experience data. Individual patient responses are nested within different nursing units, which are nested within different hospitals (Figure 1), a 3-level data structure. This nesting could be further extended to hospitals within different systems, within different geographic regions-data with a hierarchical structure. ${ }^{2,3}$ Other frequently encountered multilevel data structures include
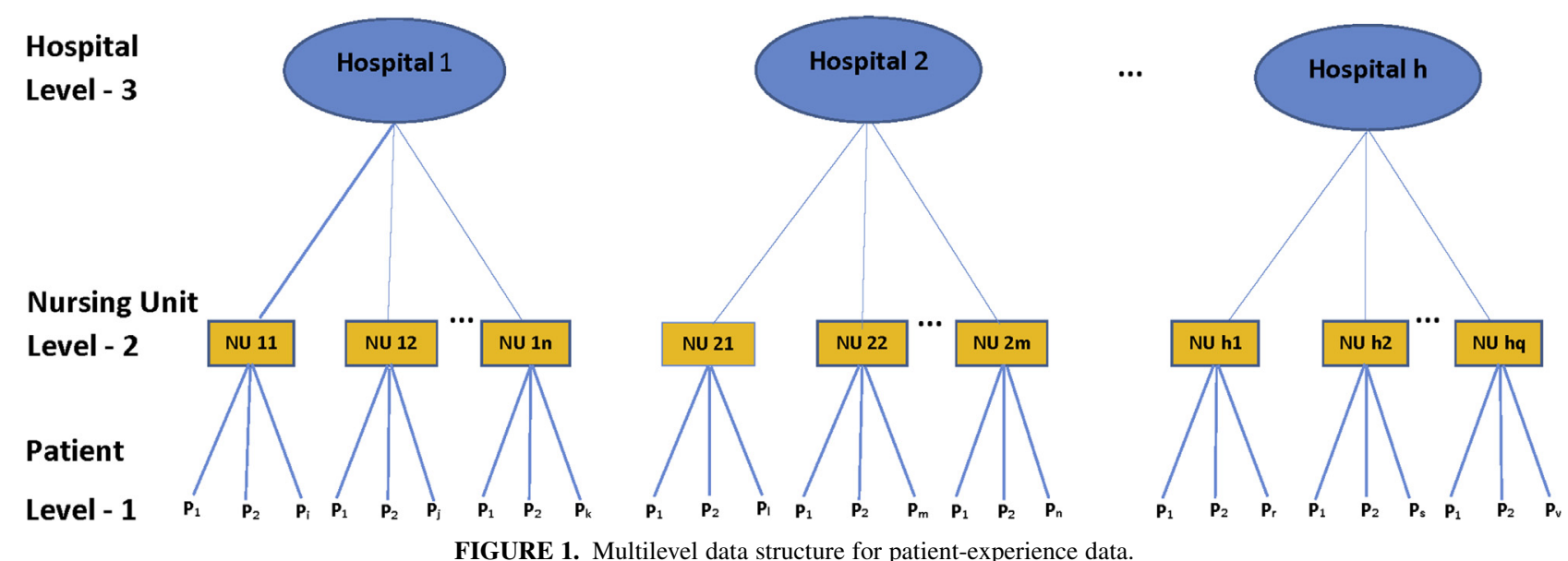

FIGURE 1. Multilevel data structure for patient-experience data. 


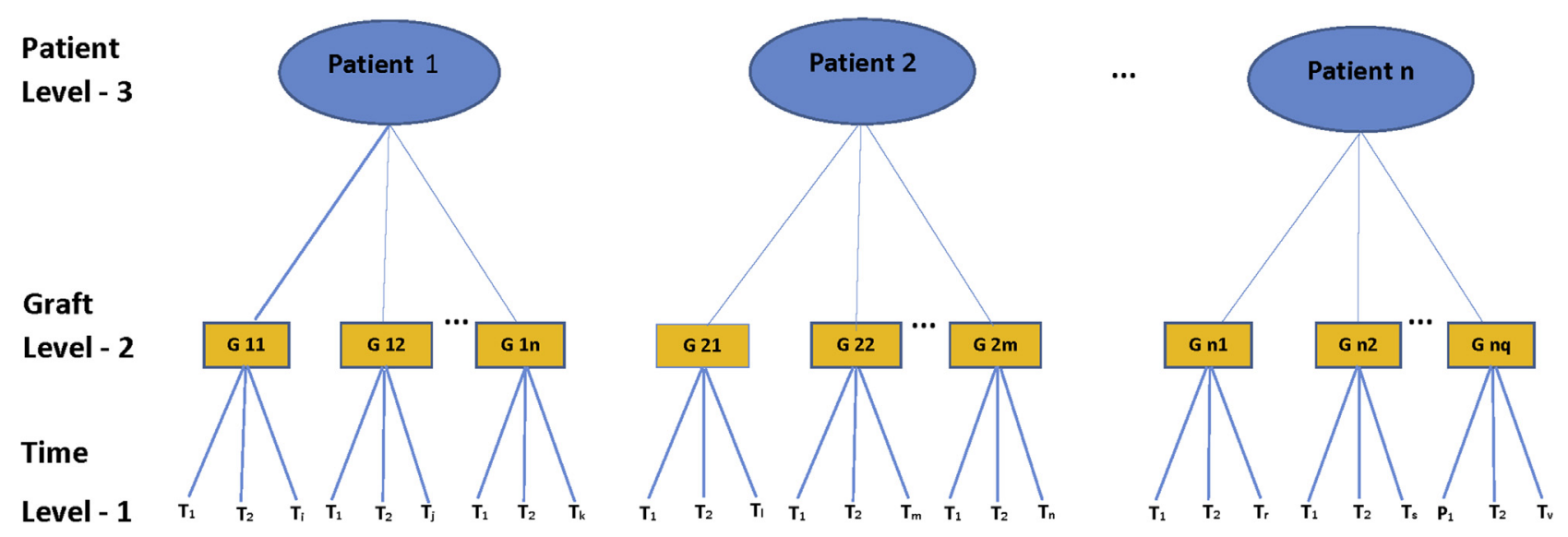

FIGURE 2. Multilevel data structure for coronary artery bypass graft patency data.

repeated measurements of spirometry after lung transplant, also a 2-level data structure, ${ }^{4}$ or coronary bypass graft stenosis measured at different time points, nested within different grafts, with graft types nested within a patient (Figure 2), a 3-level data structure. Importantly, concomitant information (potential risk factors or modulating factors) may be available at each nested level. Thus, in patient-experience data (Figure 1), one may have patient-level data (eg, age), nursing unit-level data (eg, nurse-patient ratio), and hospital-level data (eg, teaching hospital).

\section{WHY?}

Ordinary regression models assume observations are independent. However, nested observations tend to be correlated at each level, because lower-level observations share common groupings at higher levels. Failure to take these correlations into account may lead to biased estimates. Parolari and colleagues ${ }^{1}$ assessed the effect on graft patency of concomitant information from both levels, patient and graft.

\section{HOW?}

As we tell authors, proper analysis of multilevel data requires collaboration with a statistician knowledgeable in mixed-effect models or longitudinal data analysis. The language of these analyses is generally unfamiliar. What is "mixed?" Specific variables at each level, often constant across groups in a level, are called "fixed effects"; variables related to hierarchical levels themselves, often individually identified patients as in Parolari and colleagues, ${ }^{1}$ are called "random effects." Thus, "mixed effects" statistical models sort out effects at each data level.

Although we direct investigators to software for such analyses (PROC NLMIXED SAS, aML, ${ }^{5}$ HML, MLwiN ${ }^{6}$ ), this field of statistics is developing rapidly and advancing. We need to be aware of it, but we also need experts to perform the analyses and interpret the results.

\section{References}

1. Parolari A, Cavallotti L, Andreini D, Myasoedova V, Banfi C, Camera M, et al. D-dimer is associated to arterial and venous coronary artery bypass grafts occlusion. J Thorac Cardiovasc Surg. 2018;155:200-7.e3.

2. Peugh JL. A practical guide to multilevel modeling. J Sch Psychol. 2010;48: 85-112.

3. Luke DA. Multilevel Modeling. Thousand Oaks, Calif: Sage; 2004.

4. Rajeswaran J, Blackstone EH. A multiphase non-linear mixed effects model: an application to spirometry after lung transplantation. Stat Methods Med Res. 2017;26:21-42.

5. Lillard LA, Panis C. aML Multilevel Multiprocess Statistical Software, Version 2.0. Los Angeles, Calif: EconWare; 2003.

6. Browne WJ. MCMC estimation in MLwiN Version 2.32. Centre for Multilevel Modelling, University of Bristol; 2015. Available at: http://www.bris.ac.uk/ $\mathrm{cmm} / \mathrm{media} /$ software/mlwin/downloads/manuals/2-32/mcmc-web.pdf. Accessed June 8, 2017. 